\title{
A STUDY OF FRICTION MODEL PERFORMANCE IN A SKEW ROLLING PROCESS NUMERICAL SIMULATION
}

\author{
Murillo-Marrodan, A. ; Garcia, E. \& Cortes, F. \\ Faculty of Engineering, University of Deusto, Avda Universidades, 24, 48007 Bilbao, Spain \\ E-Mail: alberto.murillo@deusto.es ( ${ }^{*}$ Corresponding author)
}

\begin{abstract}
This paper studies the influence of diverse friction models on the numerical analysis of an industrial skew rolling mill using FORGE®. The originality of the present contribution is the analysis of the effect of the friction model on important parameters, namely, consumed power, plastic deformation and surface temperature. The aim is to evaluate which of these friction models is appropriate for simulating these industrial processes. The high values of temperature, pressure and sliding velocity at the contacts make the assessment of the friction model incidence on the deformation and temperature evolution fundamental, given its importance on the thermomechanical processing of materials. As a conclusion, IFUM is not valid because of its sliding velocity approach. On the other hand, Neumaier presents the highest deviations in terms of experimental power. It is concluded that Tresca is valid for this sort of processes and Norton model gives the most accurate results for friction power, related to the high sliding conditions at the contact.

(Received in March 2018, accepted in August 2018. This paper was with the authors 1 month for 2 revisions.)
\end{abstract}

Key Words: Friction Model, Friction Law, Metal Forming, Skew Rolling Mill, Numerical Analysis

\section{INTRODUCTION}

Seamless tube manufacturing mill technologies are continuously evolving and becoming more complex. The use of modelling and simulation is a key aspect for this evolution, as it has led to the development of two-roll and three-roll mills with different configurations.

However, due to the complexity of the process, most researchers use simplifications that affect important aspects. Friction is one of the factors that is generally simplified despite being crucial in metal forming processes, as it considerably influences the characteristics of the material during its processing. In continuous deformation processes like hot roll-piercing mill operations, it is responsible for driving the material through the forming rolls. However, local die-material interfaces are difficult to simulate because of the high values of temperature and pressure, and the inaccessible contact area. Major factors affecting friction during hot rolling are sliding, normal stress, material properties, lubrication condition, roughness and oxidation [1-3].

Due to the difficulty of characterising the contact in a real process, many studies have approached the problem using laboratory tests. For this purpose, test methods such as upsetting-sliding [4, 5], T-shape compression [6], Pin-on-disc [7] or the widespread ring compression [8, 9] have been used. However, Joun et al. [8] concluded that the friction evaluation curves achieved by means of the ring compression test were irrelevant for the hot rolling process that they analysed. This fact emphasises the limitations of applying laboratory results to continuous metal forming processes.

Among helical hot rolling processes, the initial piercing stage of the billet in the skew rollpiercing mill to produce seamless tubes is notably sensitive to friction. Rolls grab the billet and make it advance and rotate, while the plug opens the cavity and discs contain the lateral expansion of the pierced section.

For the study and simulation of the piercing process above described, a total of 4 to 5 different contact regions must be characterised depending on the configuration: roll-material, 
plug-material and lateral discs-material interfaces. All these contacts involve non-linearities in contact area and normal stress due to plastic deformations and relative velocities. In addition, these contact regions are usually interconnected, increasing the difficulty of its characterisation.

However, the common and crucial contact present in every possible helical hot rolling process configuration is the rolls-material one. Therefore, for this study only the roll-billet critical interface is present, which is responsible for almost the total energy consumed by the piercing mill [10].

Han et al. [11] stated that studies about complex continuous local plastic forming processes are scant. Therefore, the numerical evaluation of friction applied to the roll-billet critical interface is a step forward in this field. The aspects considered in such evaluation agree with previous studies such as the plastic deformation $[8,11,12]$ and loads between dies and piece [12].

Accordingly, experimental values of instant power consumption and billet velocity are related to the friction at the interface. Furthermore, the effect of the friction model on deformation and temperature at the interface is considered, given its importance the quality of rolled parts [13]. This way, in the present work, the performance of the considered friction models is assessed based on the simulation of a complex industrial skew rolling process.

A theoretical background of the most representative friction models used in hot metal forming is given in section 2 . Then, in section 3 the numerical model of the skew rolling mill is presented. Section 4 introduces the experimental results of the set of tests performed, which are used for the analysis of the numerical model. Afterwards, in section 5 results of the simulated cases are discussed and compared. Finally, the conclusions are presented in section 6.

\section{FRICTION MODELS IN METAL FORMING}

Friction is the phenomenon responsible for the resisting forces located at the interface of bodies in contact with relative velocity between them. A realistic description is required for the usability of the finite element (FE) simulation results. However, in hot metal forming processes friction models are abundant. Below the principal ones are presented.

\subsection{Coulomb friction model}

Coulomb's friction [14] approaches shear stress $\tau$ by means of a friction coefficient $\mu$, which multiplies the normal stress $\sigma_{\mathrm{n}}$ according to:

$$
\tau=\mu \cdot \sigma_{\mathrm{n}} \cdot \frac{v_{\text {rel }}}{\sqrt{\left\|v_{\text {rel }}\right\|^{2}+v_{\text {reg }}^{2}}}
$$

The relative velocity $v_{\text {rel }}$ and the regularisation velocity $v_{\text {reg }}$ are used for avoiding numerical stability problems when the relative velocity tends to be null. Due to its simplicity it tends to be used in sheet metal forming [15], or machining [16]. It has been applied to a skew mill simulation [17] and to characterise friction in cylindrical surfaces using the BTU test [18]. However, it is not valid for hot rolling mills, because the normal stress overcomes the billet yield stress, what leads to a overestimation of the frictional shear stress once the material shear strength $k$ is exceeded [19].

\subsection{Constant shear friction model}

Tresca or constant shear friction model [19] gives a more realistic approach when shear stress exceeds the shear strength $k$ of the material. Shear stress $\tau$ is calculated as: 


$$
\tau=m \cdot k \cdot \frac{v_{\text {rel }}}{\sqrt{\left\|v_{\text {rel }}\right\|^{2}+v_{\text {reg }}^{2}}},
$$

where coefficient $m$ stands for the friction factor and its value ranges between $0<m<1$. In case of sticking, it presents a unit value meaning that the friction shear stress in the interface is equal to the shear flow stress of the softer body. Friction stress depends on the friction factor, but also on the material shear yield strength $k$, given by:

$$
k=\frac{\bar{\sigma}}{\sqrt{3}}
$$

where $\bar{\sigma}$ is the equivalent stress. Due to its simplicity and numerical rigidity, this law is commonly used for the simulation of friction in the contacts between the billet and rolls. Several authors have used this model [20-22], with coefficients $m$ that range between 0.8 and 1. These high values imply that the conditions in the interface are interpreted as dry or sticking friction.

\subsection{Norton friction model}

Norton's friction law, also named viscoplastic friction law, is a boundary based model. It assumes a viscous behaviour of the billet material close to the contact with the tool. This model has already been implemented in hot rolling simulations [23], showing better results in terms of rolling torque and force, when compared with other models [24]. The equation of this friction law is defined by:

$$
\tau=-\alpha \cdot K \cdot\left({\sqrt{\left\|v_{\text {rel }}\right\|^{2}+v_{\text {reg }}^{2}}}^{p f-1} \cdot v_{\text {rel }},\right.
$$

where $\alpha$ is the viscoplastic friction coefficient $(0<\alpha<1)$, whose value is dependent on the normal stress $\sigma_{\mathrm{n}}, K$ is the material consistency and $p f$ the sensitivity to sliding velocity, with a similar value to the strain rate sensitivity index of the rheological model. Its value is approximately 0.15 for steel hot forming processes [25] and thus, it allows exceeding the theoretical limit of shear stress when sticking happens, at high sliding velocity values. It leads to a substantial difference compared to the other models, which are dependent on the shear yield strength of the material. $K$ is dependent on both flow stress $\sigma_{\mathrm{o}}$ and equivalent strain rate $\dot{\bar{\varepsilon}}$ according to:

$$
K=\frac{\sigma_{\mathrm{o}}}{(\sqrt{3})^{m_{\mathrm{v}}+1} \cdot \dot{\bar{\varepsilon}}^{m_{\mathrm{v}}}},
$$

where $m_{\mathrm{v}}$ is the strain rate sensitivity. The main contribution of this friction law is that it considers the existence of a thin viscoplastic interface layer, making the friction forces dependent on the relative sliding velocity.

\subsection{Neumaier friction model}

Neumaier friction model [26] is able to describe the changing contact conditions regarding the real contact area between working piece and die. The shear stress is then calculated as:

$$
\tau=m \cdot k \cdot\left(1-\exp \left(-\frac{\left|\sigma_{\mathrm{n}}\right|}{\sigma_{\mathrm{y}}}\right)\right) \cdot f\left(v_{\mathrm{rel}}\right),
$$

where $m$ is the constant friction factor, $k$ the shear yield strength, $\sigma_{\mathrm{n}}$ the normal stress and $\sigma_{\mathrm{y}}$ the yield stress. It is based on the assumption that the real contact area is smaller than the apparent area. When the asperities are worn there is saturation in the contact area. This 
phenomenon is considered by the relation of normal pressure to shear yield strength. The sliding influence is determined by:

$$
f\left(v_{\text {rel }}\right)=\frac{2}{\pi} \cdot \arctan \left(\frac{v_{\text {rel }}}{C}\right),
$$

where the parameter $C$ serves to adjust the influence of the sliding velocity on the frictional shear stress [26]. High values of $C$ lead to low friction at the interface, while low values can cause numerical convergence problems. The arctangent is used as a mathematical idealisation of the nonlinear frictional contact behaviour.

\subsection{IFUM friction model}

IFUM model [26] has been developed for a hot forging operation. Its main contribution is the capability of distinguishing between stress states of low and high contact pressures, or in other words between fully elastic and plastic deformation. The shear stress is given by:

$$
\tau=\left[0.3 \cdot\left(1-\frac{\bar{\sigma}}{\sigma_{\mathrm{y}}}\right) \cdot \sigma_{\mathrm{n}}+m \cdot k \cdot \frac{\bar{\sigma}}{\sigma_{\mathrm{y}}} \cdot\left(1-\exp \left(-\frac{\left|\sigma_{\mathrm{n}}\right|}{\sigma_{\mathrm{y}}}\right)\right)\right] \cdot f\left(v_{\mathrm{rel}}\right)
$$

But as elasticity can be neglected in the skew mill operation, the resulting mathematical expression for the calculation of the shear stress presents Neumaier's similar structure yielding Eq. (6). However, it presents differences regarding the influence of the sliding velocity, stating that the higher the sliding velocity the lower the frictional stress will be. The sliding velocity term of the equation yields:

$$
f\left(v_{\text {rel }}\right)=\exp \left(-\frac{1}{2} \cdot\left(\frac{v_{\text {rel }}}{C}\right)^{2}\right)
$$

In this case, parameter $C$ shows the opposite effect on the shear stress [26]. The higher is the value of $C$, the higher is the friction when high values of relative velocity are present.

In conclusion, several friction laws can be used for the simulation of a skew hot rolling process. Coulomb is excluded from the study because of exceeding the shear strength. Among which may be valid, differences are observed when evaluating the influence of some parameters, namely sliding velocity or the state of stress of the material. The effect of the sliding velocity on the predicted shear stress for each friction model is shown in Fig. 1.

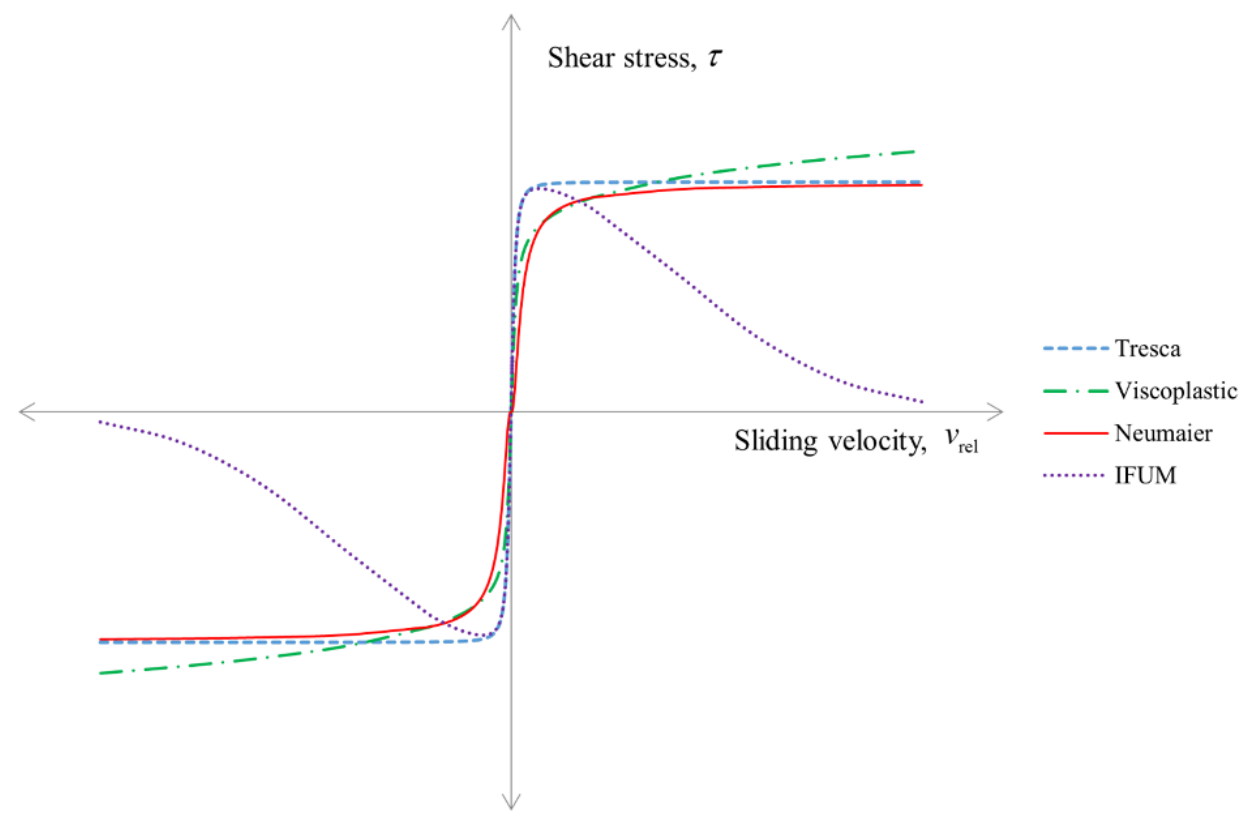

Figure 1: Effect of sliding velocity on shear stress according to the evaluated friction laws. 
It is observed how both Neumaier and IFUM models are limited upwards by the constant shear stress model, while viscoplastic friction model can predict higher values when the relative velocity is high enough. Then, for the numerical evaluation of friction, a FE model of the skew rolling process has been developed considering only Tresca, Norton, Neumaier and IFUM friction laws in the contact between rolls and billet.

\section{NUMERICAL MODEL}

The FE model of the skew rolling mill is simulated using the FE software FORGE®. It includes both rolls and the billet, which is simulated with 25,000 tetrahedral linear P1+ elements. In addition, a guide at the entrance of the piercing mill is included and also a press for reproducing the thrust bench action. The scheme of the process and the numerical model are presented in Fig. 2.
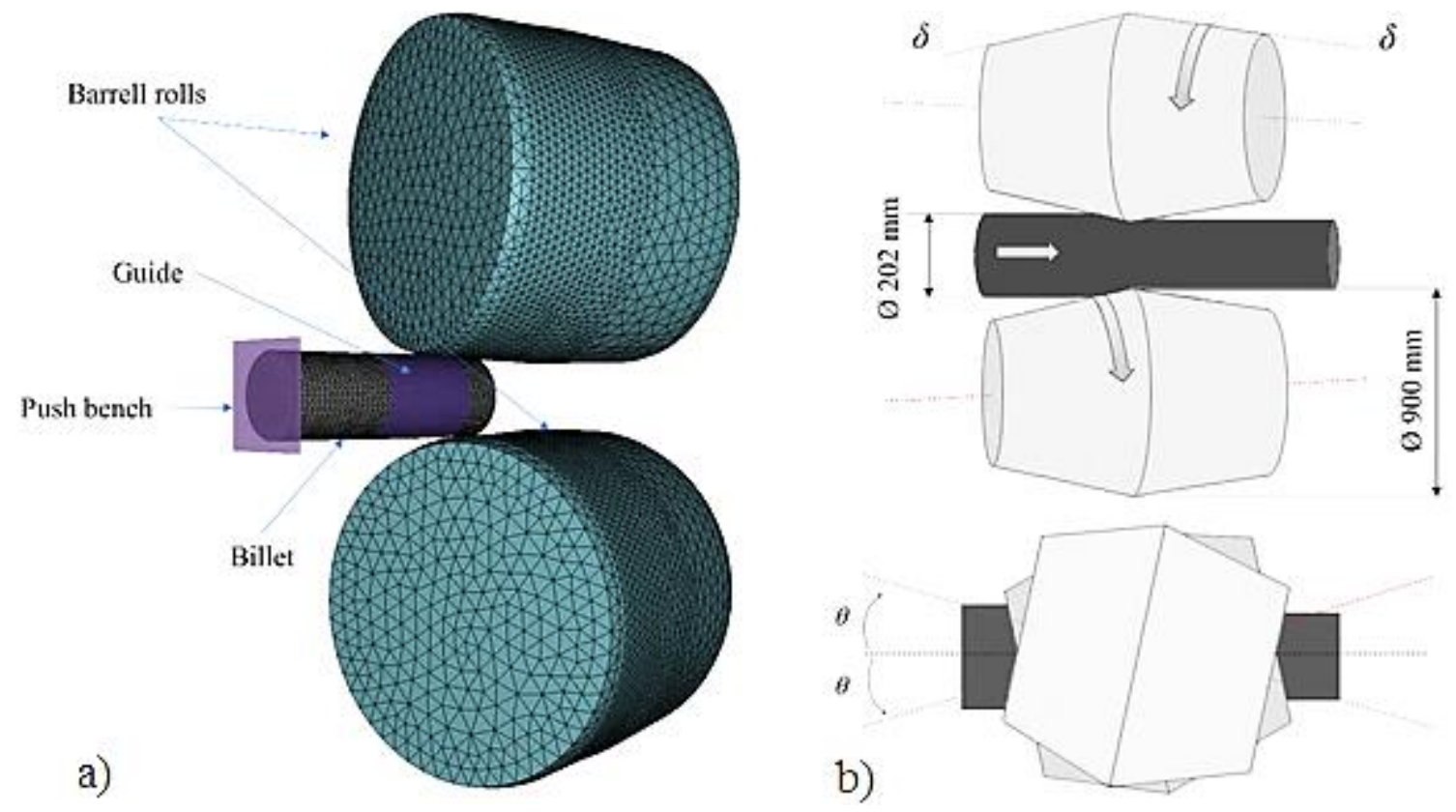

Figure 2: Skew-rolling mill representation: a) numerical model, b) scheme.

Rolls present a barrel shape, with a maximum diameter of $900 \mathrm{~mm}$ and rotate at an angular velocity of $111 \mathrm{rpm}$ in clockwise direction. They are separated $180 \mathrm{~mm}$ and present a roll profile angle $\delta$ of $1.5^{\circ}$ and a feed angle $\theta$ of $12^{\circ}$. The working piece consists of a $202 \mathrm{~mm}$ diameter round continuously cast bar made of low-alloyed steel DIN C15D.

The initial temperature of the billet is $1250{ }^{\circ} \mathrm{C}$, assuming a temperature of $50{ }^{\circ} \mathrm{C}$ in the rolls, with a heat transfer coefficient of $10,000 \mathrm{~W} / \mathrm{m}^{2} \mathrm{~K}$ for the contact and $10 \mathrm{~W} / \mathrm{m}^{2} \mathrm{~K}$ for the surrounding air convection [20].

The model assumes a rigid-viscoplastic approach, Hansel-Spittel constitutive law is used with the C15D steel data of FORGE® NxT database [25], which depends on the equivalent strain $\bar{\varepsilon}$, equivalent strain rate $\dot{\bar{\varepsilon}}$ and temperature $T$, yielding:

$$
\bar{\sigma}(\bar{\varepsilon}, \dot{\bar{\varepsilon}}, T)=752.54 \cdot \exp (-0.00219 \cdot T) \cdot \bar{\varepsilon}^{-0.1523} \cdot \dot{\bar{\varepsilon}}^{0.14688} \cdot \exp \left(\frac{-0.0486}{\bar{\varepsilon}}\right)
$$

The friction at the interface has been modelled using the above mentioned friction laws, varying the coefficients for the evaluation of their impact. This way, it is possible to discern which of the friction models is valid for the simulation of this sort of hot forming processes.

In Table I the simulated cases are listed, showing the values of the coefficients for each case and assigning an ID for each simulation that will be used henceforth. The election of the 
coefficients is based on the consulted literature, not aiming to find the optimised value of the coefficients for each friction law, but to analyse their differences.

Table I: Simulated cases, friction law and coefficient associated.

\begin{tabular}{|c|c|c|c|c|c|c|}
\hline Case & Simulation ID & Friction model & $\boldsymbol{m}$ & $\boldsymbol{\alpha}$ & $\boldsymbol{p f}$ & $\boldsymbol{C}$ \\
\hline 1 & IfumC10 & IFUM & 1 & - & - & 10 \\
\hline 2 & IfumC200 & IFUM & 1 & - & - & 200 \\
\hline 3 & NeuC10 & Neumaier & 1 & - & - & 10 \\
\hline 4 & NeuC1 & Neumaier & 1 & - & - & 1 \\
\hline 5 & Neu & Neumaier & 1 & - & - & 0 \\
\hline 6 & Visco07 & Norton & - & 0.7 & 0.14688 & - \\
\hline 7 & Visco08 & Norton & - & 0.8 & 0.14688 & - \\
\hline 8 & Visco09 & Norton & - & 0.9 & 0.14688 & - \\
\hline 9 & Tresca07 & Tresca & 0.7 & - & - & - \\
\hline 10 & Tresca08 & Tresca & 0.8 & - & - & - \\
\hline 11 & Tresca09 & Tresca & 0.9 & - & - & - \\
\hline
\end{tabular}

\section{EXPERIMENTAL DATA}

A set of 6 industrial tests were performed by Tubos Reunidos Industrial [27]. The tests consisted of rolling steel bars of $0.6 \mathrm{~m}$ showing an average duration of $0.92 \mathrm{~s}$ when the bar exited the mill. From the industrial tests, important parameters were measured in order to compare them to the numerical results, namely, instant power, process time and, as a result of the latter, the velocity of the billet.

As the industrial tests were performed in an industrial rolling mill, the experimental records corresponded to the electrical current consumed during the rolling operation. The current consumed during the 6 industrial tests is given in Fig. 3.

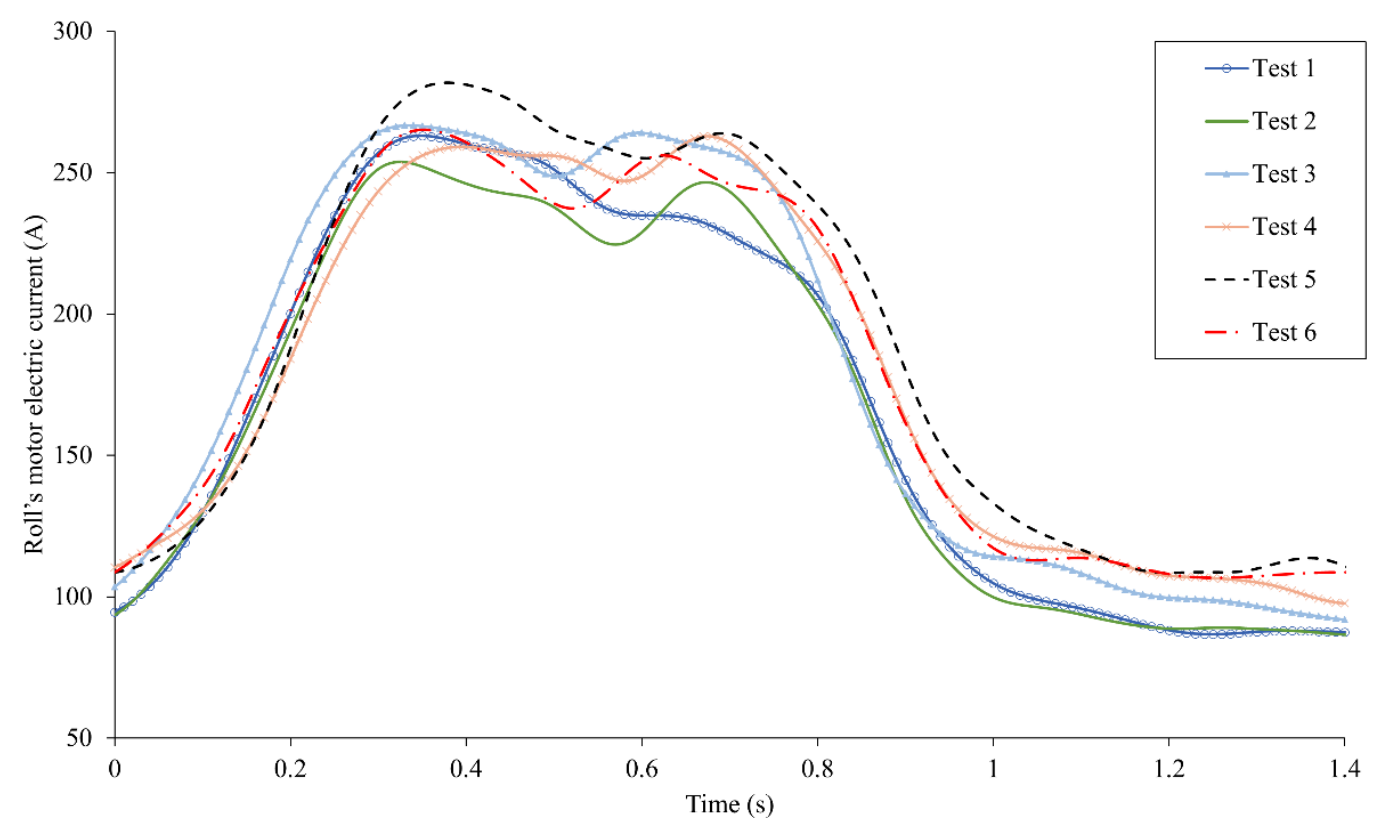

Figure 3: Current-time curves recorded in the set of industrial tests.

From these curves, the average current value was transformed into power using the specifications of the electric motor (see Fig. 5). In the resulting power consumption experimental curve, the steady phase has been considered (see Fig. 5) for the study of the average instant power, yielding a value of $2484 \mathrm{~kW}$. 
Besides, the experimental mean velocity value corresponds to the displacement of the billet (measured at the tail of the billet) during the piercing operation, divided by the perforation time. The total displacement of the tail is the billet length $(600 \mathrm{~mm})$ plus the distance that the tail covers until the process is completed $(254 \mathrm{~mm})$, as illustrated in Fig. 4.

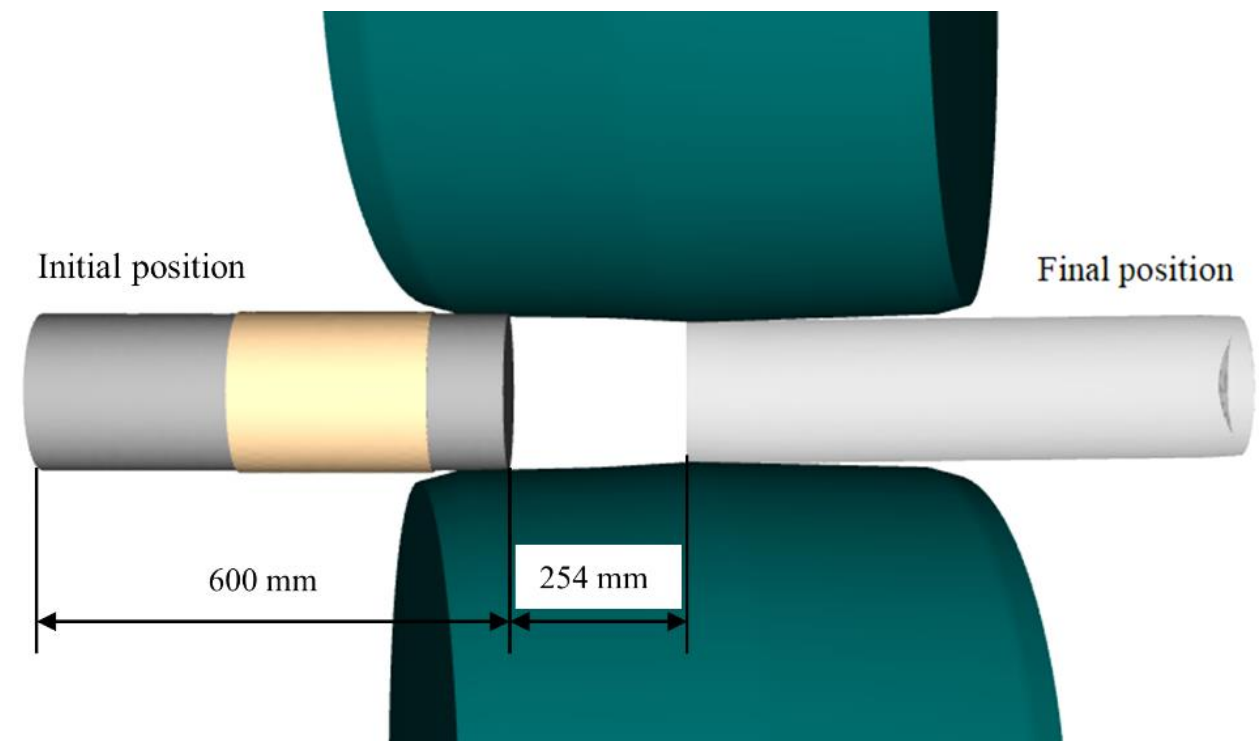

Figure 4: Distance that covers the billet throughout the process.

Therefore, the result of dividing the distance covered by the process time results in 928.7 $\mathrm{mm} / \mathrm{s}$. It is considered the experimental mean velocity of the billet (measured at its tail) and thus is compared to the value given by the simulations.

\section{RESULTS AND DISCUSSION}

In this section, power and velocity results of the numerical models are compared to those of the industrial tests in order to evaluate the appropriateness of each law. Friction models showing a higher compliance with the experimental results are further analysed by comparing their metal flow and temperature results.

\subsection{Power and velocity}

The influence of the friction model and the friction coefficient on the instant power and velocity results of the simulations is analysed. The skew rolling studied in this paper is strongly influenced by friction in the contact between rolls and billet. In fact, both experimental tests and numerical models show that if the friction generated at the contact is not high enough the billet is not able to pass through the rolls. Therefore, first step in the analysis of the friction models is to verify that they are able of producing the minimum friction force to accomplish the process.

On the one hand, IFUM and Neumaier models have difficulties in generating this minimum force for the process to be completed. IFUM was evaluated using $C$ values of 10 and 200 (cases 1 and 2) of Table I. These values were selected considering the value used by the authors for the validation of the model $(C=150)$ [26]. However, they are not able to force the billet through the rolls. It is explained by the high sliding contact conditions at the beginning of the process, when rolls are rotating and the piece is not. It leads to a very low friction at the interface (see Fig. 1), that is not sufficient for the movement of the billet. Therefore, as the roll initial bite cannot be reproduced, this model is no longer considered in the study and is not suitable for this sort of processes. 
Neumaier model, by contrast, presents a friction force that increases with sliding velocity up to a limit (see Fig. 1). Therefore, the initial high sliding contact does not affect the friction stress. However, using $C$ parameter values similar to the author proposed ones, neither case 3 $(C=10)$ nor case $4(C=1)$ are able to complete the entire process. Reducing the value of $C$ would increase friction forces, however, the low values required for this process lead numerical convergence problems [12]. Therefore, instead of minimising $C$ coefficient, an additional case where $f\left(v_{\text {rel }}\right)$ is not considered $(C=0)$ has been simulated, reproducing correctly the process.

Next, the results of power and velocity of the models that are able to force the billet through the rolls, namely, Visco, Tresca and Neu $(C=0)$ are analysed. Table II gathers the velocity values of the simulated cases and their deviation with respect the experimental value.

Table II: Average velocities of the distinct cases during the steady phase.

\begin{tabular}{|c|c|c|}
\hline Simulation ID & Steady average velocity $(\mathrm{mm} / \mathrm{s})$ & Deviation $(\%)$ \\
\hline Neu & 927.3 & -0.2 \\
\hline Visco07 & 917.1 & -1.2 \\
\hline Visco08 & 931.8 & 0.3 \\
\hline Visco09 & 936.0 & 0.8 \\
\hline Tresca07 & 925.2 & -0.4 \\
\hline Tresca08 & 931.3 & 0.3 \\
\hline Tresca09 & 933.0 & 0.5 \\
\hline
\end{tabular}

Results show that both, the friction model as well as the friction coefficient, affect the mean billet velocity. The friction model determines the displacement of the working piece, as the relative velocity at the interface is directly affected by the frictional force at the contact. In fact, the higher the coefficient is the higher is the rolling advance velocity, for each of the models. Since differences between models are not significant, it is considered that all of them are capable of reproducing the velocity of lamination correctly and their differences are no longer studied.

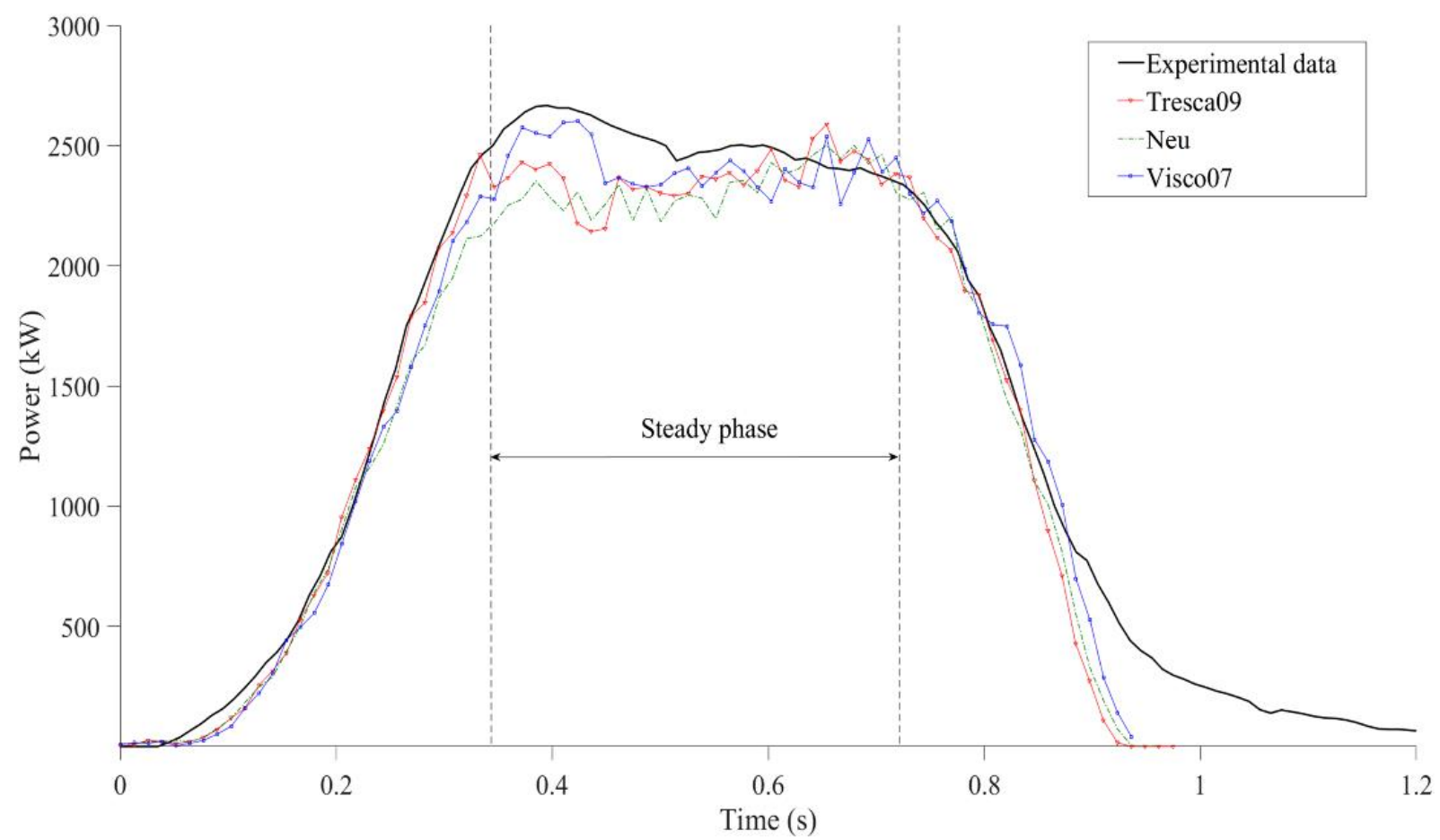

Figure 5: Comparison between the experimental and numerical instant power consumptions. 
Regarding power consumption, Fig. 5 shows that all models reproduce the experimental power trend, which agrees with velocity results. However, differences are appreciated when the mean power values of the steady phase are analysed.

For the analysis of the consumed power during the steady phase, the total power value is decomposed into its plastic and frictional components in Fig. 6. It provides a better understanding and allows the evaluation of the effect of both friction model and coefficient election on the power consumed.

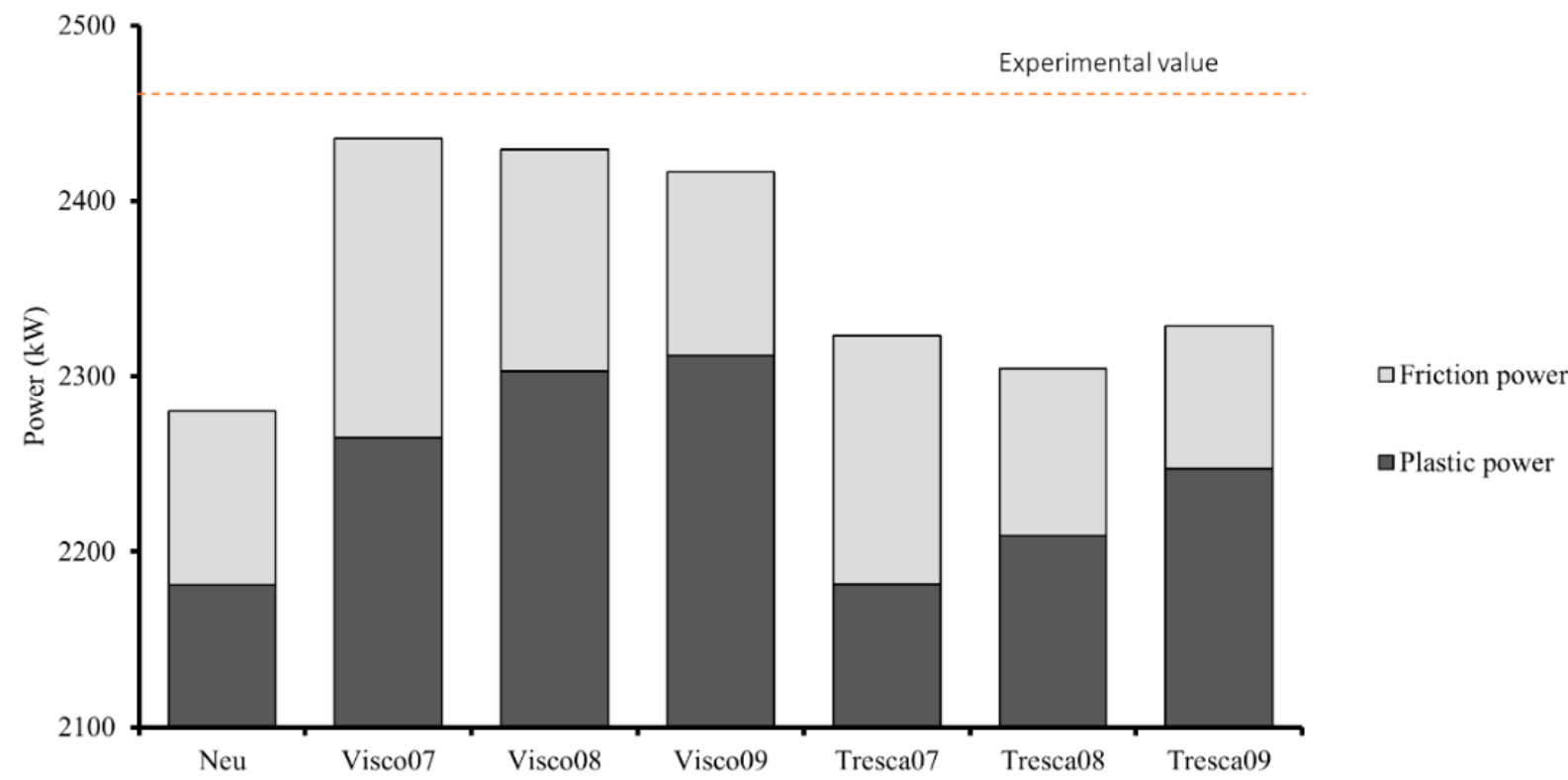

Figure 6: Decomposition of the total power into plastic and frictional components.

Results show that friction model election and their coefficient values strongly affect the power consumed. The plastic power is mainly determined by the global deformation rate of the process. When the advance velocity is higher (higher friction coefficients) the deformation rate is increased and so the plastic power. However, depending on the friction model, for similar advance velocities plastic power values are different. It is explained by the differences of stress over the surface. Being similar the global deformation rates and assuming similar normal stresses, the main difference is therefore introduced by the variation of shear stress on the surface.

Regarding the friction power, it depends on the shear stress and sliding velocity. For a similar friction model, the higher is the coefficient the higher is the shear stress on the surface, but as the billet advance velocity is increased, the relative velocity is lowered explaining why the friction power decreases. However, under similar conditions of relative velocity at the interface, viscoplastic model gives comparatively a higher friction power output, since shear stress can overcome the shear strength of the material when sufficient relative velocity is present (see Fig. 1).

Neumaier friction model, despite reproducing correctly the experimental power consumption trend when the parameter $C$ is minimised, presents the highest deviation in terms of average instant power. The reason is the term that relates the normal and equivalent stresses, added to Tresca friction law. In this process, the normal stress does not highly overcome the equivalent stress at the contact, leading to a lower shear output of the model compared to Tresca with a similar coefficient value.

Tresca and viscoplastic friction models are both capable of reproducing the experimental advance velocity. However, the viscoplastic model is the one that shows the best compliance with the experimental average instant power value. Therefore, these two friction models are 
considered the most appropriate for the simulation of hot rolling mill processes and thus are further evaluated.

\subsection{Deformation}

At the sight of the previous results, in this section Tresca and viscoplastic friction laws are compared in terms of material deformation, using the equivalent plastic strain. A coefficient value of 0.7 and 0.8 is considered for each of the models. In this manner, it is possible to identify whether the friction model and/or the friction coefficient affect the material flow. Results of the surface effective strain field are shown in Fig. 7.
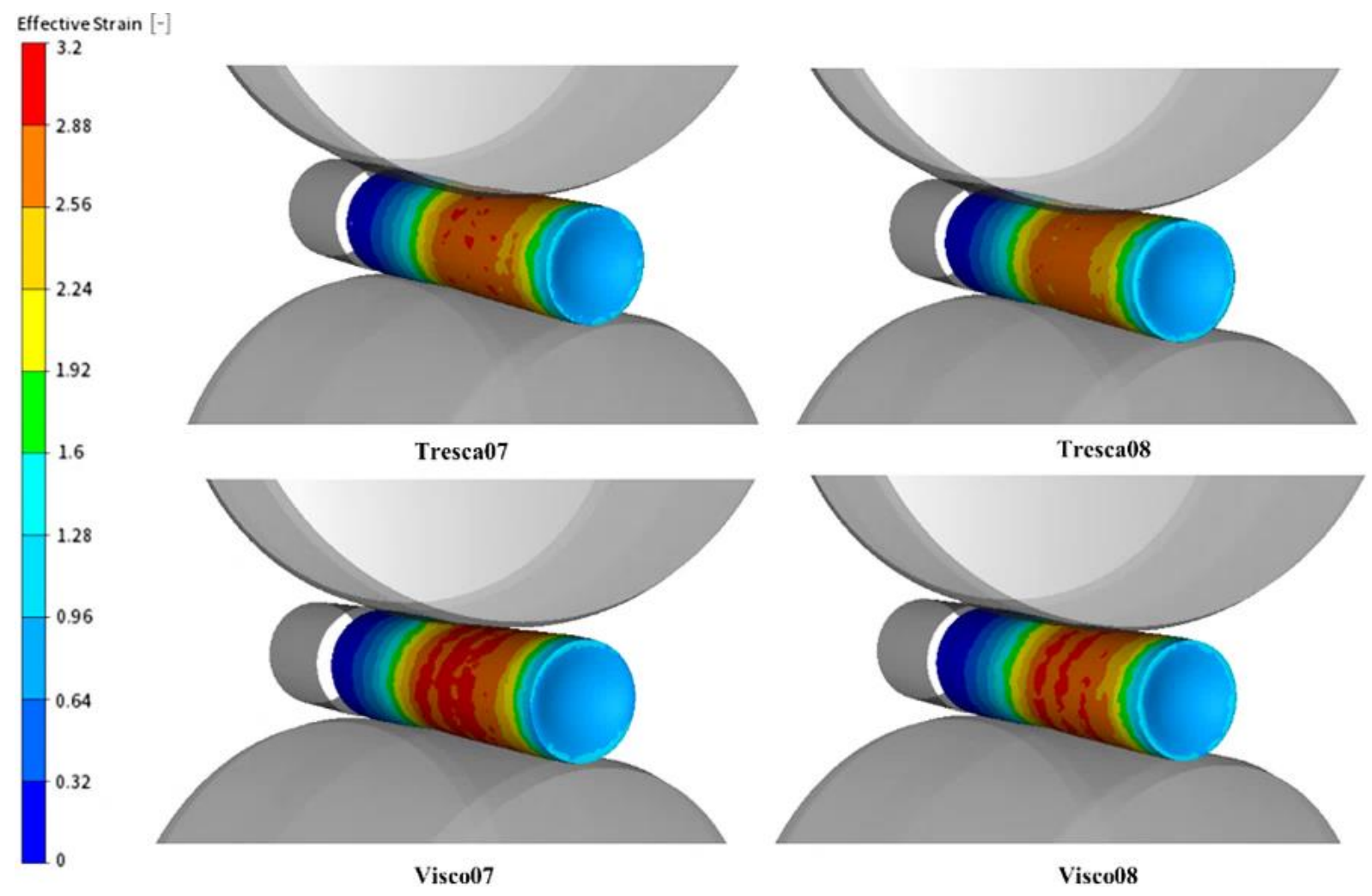

Figure 7: Effective plastic strain results.

From Fig. 7, it can be pointed out that viscoplastic model shows a higher value of superficial effective plastic strain compared to Tresca. In addition, in both cases, for a similar friction model, the effective plastic strain value is higher when the friction coefficient value is lower. Therefore, it can be stated that both friction model and coefficient values have an impact on the deformation of the working piece.

The differences between friction models are caused by the variations in the local equivalent strain rate values. The equivalent strain rate values measured at the contact region, where the distance between the rolls is minimal, are presented in Table III.

Table III: Equivalent strain rate local values.

\begin{tabular}{|c|c|}
\hline Simulation ID & Equivalent strain rate $\left(\mathrm{s}^{-1}\right)$ \\
\hline Visco07 & 33.49 \\
\hline Visco08 & 32.21 \\
\hline Tresca07 & 30.03 \\
\hline Tresca08 & 28.67 \\
\hline
\end{tabular}


From Table III, it can be pointed out that viscoplastic friction model presents higher values of local strain rate at the interface compared to the respective Tresca cases. Besides, for a similar friction model differences are appreciable when the coefficient is modified. For both friction models, the case with lower friction coefficient shows higher values of deformation not only because of the higher values of strain rate, but also for the higher time that the material is in contact with the rolls.

Hence, the impact of friction model on material deformation is proved, leading to a higher local deformation value at the interface when viscoplastic model is used, which is directly dependent on the contact conditions. When sufficient relative velocity is present at the interface, viscoplastic model predicts a higher shear stress than Tresca model (see Fig. 1). This fact explains why viscoplastic model predicts also slightly higher equivalent strain rate values, as shown in Table III.

\subsection{Temperature}

A fundamental parameter in hot forming processes is the temperature of the working piece. In this section Tresca and viscoplastic friction laws are compared in terms of this parameter. As mentioned in section 3, the initial temperature of the billet is $1250{ }^{\circ} \mathrm{C}$. The evolution of temperature is dependent on many factors, but the effect of friction on temperature evolution is isolated for assessing its impact on the simulation. For this purpose, convection, radiation and conduction are similar in all the numerical models, giving as a result the temperatures shown in Fig. 8.
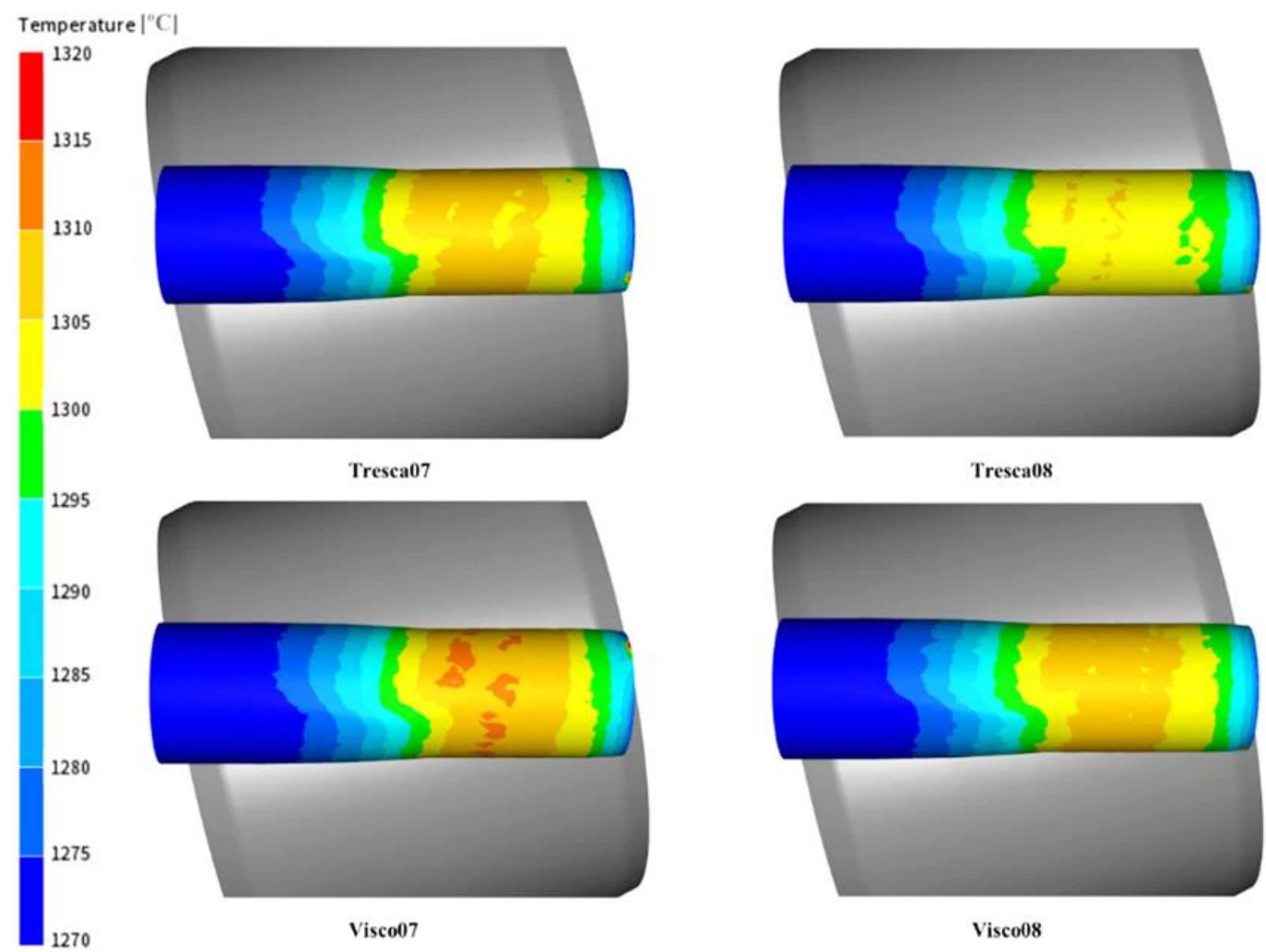

Figure 8: Temperature values during the hot skew rolling of the billet. 
Temperature differences between the considered cases are appreciated. They can be caused, on the one hand, by differences in volumetric heat dissipation due to plastic strain $\dot{W}$, which is given by:

$$
\dot{W}=\int \eta \cdot \bar{\sigma} \cdot \dot{\bar{\varepsilon}} \cdot \mathrm{d} V
$$

where $\eta$ is the strain efficiency, which is maintained in all the cases. And, on the other hand, by the friction power dissipated at the interface $\phi_{\mathrm{fr}}$, calculated as:

$$
\phi_{\mathrm{fr}}=\int \frac{b_{1}}{b_{1}+b_{2}} \cdot \tau \cdot v_{\mathrm{rel}} \cdot \mathrm{d} S
$$

where $b_{1}$ and $b_{2}$ are the effusivity coefficients, that are similar for all the simulated cases and the rest of the equation corresponds to the friction power.

The overall deformation of the billet is conducted at a similar rate in the four considered cases, so that temperature variations caused by differences in plastic strain heat dissipation can be considered omissible.

However, friction power results have shown higher differences and as there is a direct relation between friction power and temperature, viscoplastic cases show higher superficial temperature values than the respective Tresca cases. It agrees with friction power results shown in section 5.1. Besides, for a similar friction model, the case that presents a lower coefficient value, shows higher temperature on the surface, which is explained by the higher value of relative velocity at the contact and thus friction power. Hence, it proves how the election of the friction model also affects the superficial temperature of the deformed piece, although the differences are not extremely high.

\section{CONCLUSIONS}

In this paper, the influence of friction modelling on the simulation of the skew rolling process has been analysed. A total number of 4 friction models (Neumaier, IFUM, Tresca and Norton) are compared with experimental results of the process, namely, velocity and power consumption. In addition, those friction laws that show a better compliance with the experimental results are further compared in terms of deformation and temperature.

It has been concluded that IFUM friction model is not valid for this process because of its interpretation of relative velocity at the interface that prevents the initial billet bite to be completed. Neumaier friction model, in contrast, reproduces the rolling velocity (only with very low values of $C$ ) and shows the highest discrepancies between the calculated and experimental power values. Consequently, only Tresca and viscoplastic friction models have shown good compliance with both power and velocity experimental results. However, Norton friction law approach is clearly more accurate in terms of power consumed.

Tresca and viscoplastic friction models have been further compared, analysing their effect on the effective plastic deformation and temperature evolution on the surface of the billet. It has been demonstrated how the election of the friction model and coefficient can lead to different local deformation at the contact. Finally, isolating the effect of friction on the temperature evolution, it is shown that the election of friction model and coefficient result in temperature differences up to $15^{\circ} \mathrm{C}$ at the contact. In conclusion, Norton friction model is the most adequate for the simulation of hot skew rolling processes in which sliding velocity ranges from moderate to high values.

\section{ACKNOWLEDGEMENT}

The authors gratefully acknowledge Tubos Reunidos Industrial for sharing relevant experimental data from the industrial tests. 


\section{REFERENCES}

[1] Cheng, X.; Jiang, Z.; Wei, D.; Hao, L.; Wu, H.; Xia, W.; Zhang, X.; Luo, S.; Jiang, L. (2017). Effects of surface preparation on tribological behaviour of a ferritic stainless steel in hot rolling, Wear, Vols. 376-377, Part B, 1804-1813, doi:10.1016/j.wear.2017.01.106

[2] Lenard, J. G.; Barbulovic-Nad, L. (2002). The coefficient of friction during hot rolling of low carbon steel strips, Journal of Tribology, Vol. 124, No. 4, 840-845, doi:10.1115/1.1454106

[3] Vergne, C.; Boher, C.; Gras, R.; Levaillant, C. (2006). Influence of oxides on friction in hot rolling: Experimental investigations and tribological modelling, Wear, Vol. 260, No. 9-10, 957975, doi:10.1016/j.wear.2005.06.005

[4] Brocail, J.; Watremez, M.; Dubar, L. (2010). Identification of a friction model for modelling of orthogonal cutting, International Journal of Machine Tools and Manufacture, Vol. 50, No. 9, 807-814, doi:10.1016/j.ijmachtools.2010.05.003

[5] Vidal-Sallé, E.; Dubar, M.; Boyer, J.-C.; Dubar, L. (2010). FEM numerical simulation of the warm and hot upsetting sliding test, International Journal of Material Forming, Vol. 3, Suppl. 1, 315-318, doi:10.1007/s12289-010-0770-8

[6] Fereshteh-Saniee, F.; Badnava, H.; Pezeshki-Najafabadi, S. M. (2011). Application of T-shape friction test for AZ31 and AZ80 magnesium alloys at elevated temperatures, Materials \& Design, Vol. 32, No. 6, 3221-3230, doi:10.1016/j.matdes.2011.02.042

[7] Kučera, M.; Rusnák, J.; Kadnár, M.; Malý, V. (2016). Analysis of tribologic properties of selected steels, Technical Gazette, Vol. 23, No. 3, 647-651, doi:10.17559/TV-20130724104528

[8] Joun, M. S.; Moon, H. G.; Choi, I. S.; Lee, M. C.; Jun, B. Y. (2009). Effects of friction laws on metal forming processes, Tribology International, Vol. 42, No. 2, 311-319, doi:10.1016/ j.triboint.2008.06.012

[9] Shahriari, D.; Amiri, A.; Sadeghi, M. H. (2010). Study on hot ring compression test of nimonic 115 superalloy using experimental observations and 3D FEM simulation, Journal of Materials Engineering and Performance, Vol. 19, No. 5, 633-642, doi:10.1007/s11665-009-9522-7

[10] Murillo-Marrodán, A.; García, E.; Cortés, F. (2017). Friction modelling of a hot rolling process by means of the Finite Element Method, Proceedings of the World Congress on Engineering, Vol. II, 965-969

[11] Han, X.; Hua, L. (2012). Friction behaviors in cold rotary forging of 20CrMnTi alloy, Tribology International, Vol. 55, 29-39, doi:10.1016/j.triboint.2012.05.012

[12] Balasundar, I.; Raghu, T. (2010). Effect of friction model in numerical analysis of equal channel angular pressing process, Materials \& Design, Vol. 31, No. 1, 449-457, doi:10.1016/ j.matdes.2009.05.029

[13] Wu, Z. J.; Peng, W. F.; Shu, X. D. (2017). Influence of rolling temperature on interface properties of the cross wedge rolling of $42 \mathrm{CrMo} / \mathrm{Q} 235$ laminated shaft, The International Journal of Advanced Manufacturing Technology, Vol. 91, No. 1-4, 517-526, doi:10.1007/s00170-0169734-6

[14] Coulomb, C. A. (1821). Théorie des machines simples: en ayant égard au frottement de leurs parties et à la roideur des cordages, Bachelier, Paris

[15] Trzepiecinski, T.; Lemu, H. G.; Fejkiel, R. (2017). Numerical simulation of effect of friction directionality on forming of anisotropic sheets, International Journal of Simulation Modelling, Vol. 16, No. 4, 590-602, doi:10.2507/IJSIMM16(4)3.392

[16] Deng, W. J.; Zhang, J. Y.; Liu, L. W.; He, D.; Xia, W. (2017). Simulation analysis of a new chips recycling process termed forming extrusion cutting, International Journal of Simulation Modelling, Vol. 16, No. 4, 694-706, doi:10.2507/IJSIMM16(4)CO16

[17] Zhao, Y.; Yu, E.; Yan, T. (2010). Deformation analysis of seamless steel tube in cross rolling piercing process, 2010 International Conference on Computer Design and Applications, Vol. 3, 320-323, doi:10.1109/ICCDA.2010.5541258

[18] Trzepieciński, T.; Lemu, H. G. (2015). Proposal for an experimental-numerical method for friction description in sheet metal forming, Strojniški vestnik - Journal of Mechanical Engineering, Vol. 61, No. 6, 383-391, doi:10.5545/sv-jme.2015.2404

[19] Valberg, H. S. (2010). Applied Metal Forming: Including FEM Analysis, Cambridge University Press, Cambridge 
[20] Ghiotti, A.; Fanini, S.; Bruschi, S.; Bariani, P. F. (2009). Modelling of the Mannesmann effect, CIRP Annals, Vol. 58, No. 1, 255-258, doi:10.1016/j.cirp.2009.03.099

[21] Komori, K. (2005). Simulation of Mannesmann piercing process by the three-dimensional rigidplastic finite-element method, International Journal of Mechanical Sciences, Vol. 47, No. 12, 1838-1853, doi:10.1016/j.ijmecsci.2005.07.009

[22] Lu, L.; Wang, Z.; Wang, F.; Zhu, G.; Zhang, X. (2011). Simulation of tube forming process in Mannesmann mill, Journal of Shanghai Jiaotong University (Science), Vol. 16, No. 3, 281-285, doi:10.1007/s12204-011-1144-1

[23] Nalawade, R. S.; Puranik, A. J.; Balachandran, G.; Mahadik, K. N.; Balasubramanian, V. (2013). Simulation of hot rolling deformation at intermediate passes and its industrial validity, International Journal of Mechanical Sciences, Vol. 77, 8-16, doi:10.1016/j.ijmecsci.2013.09.017

[24] Duan, X.; Sheppard, T. (2002). Three dimensional thermal mechanical coupled simulation during hot rolling of aluminium alloy 3003, International Journal of Mechanical Sciences, Vol. 44, No. 10, 2155-2172, doi:10.1016/S0020-7403(02)00164-9

[25] FORGE ${ }^{\circledR}$ NxT. Transvalor, from http://www.transvalor.com/en/cmspages/forge-nxt.32.html, accessed 1-3-2018

[26] Behrens, B.-A.; Bouguecha, A.; Hadifi, T.; Mielke, J. (2011). Advanced friction modeling for bulk metal forming processes, Production Engineering, Vol. 5, No. 6, 621-627, doi: $10.1007 / \mathrm{s} 11740-011-0344-8$

[27] Barco, J. (2017). Skew rolling mill industrial tests, Internal Tubos Reunidos Industrial report: unpublished 